\title{
In vivo temporal and spatial profile of leukocyte adhesion and migration after experimental traumatic brain injury in mice
}

Susanne M Schwarzmaier ${ }^{1,2,4}$, Ricarda Zimmermann ${ }^{1}$, Niamh B McGarry², Raimund Trabold', Seong-Woong Kim ${ }^{1,2}$ and Nikolaus Plesnila ${ }^{1,2,3^{*}}$

\begin{abstract}
Background: Leukocytes are believed to be involved in delayed cell death following traumatic brain injury (TBI). However, data demonstrating that blood-borne inflammatory cells are present in the injured brain prior to the onset of secondary brain damage have been inconclusive. We therefore investigated both the interaction between leukocytes and the cerebrovascular endothelium using in vivo imaging and the accumulation of leukocytes in the penumbra following experimentally induced TBI.

Methods: Experimental TBI was induced in C57/Bl6 mice $(n=42)$ using the controlled cortical impact (CCI) injury model, and leukocyte-endothelium interactions (LEI) were quantified using both intravital fluorescence microscopy (IVM) of superficial vessels and 2-photon microscopy of cortical vessels for up to $14 \mathrm{~h}$ post-CCl. In a separate experimental group, leukocyte accumulation and secondary lesion expansion were analyzed in mice that were sacrificed $15 \mathrm{~min}, 2,6,12,24$, or $48 \mathrm{~h}$ after $\mathrm{CCl}(\mathrm{n}=48)$. Finally, leukocyte adhesion was blocked with anti-CD18 antibodies, and the effects on LEl and secondary lesion expansion were determined $16(n=12)$ and $24 \mathrm{~h}(\mathrm{n}=21)$, respectively, following TBI.

Results: One hour after TBI leukocytes and leukocyte-platelet aggregates started to roll on the endothelium of pial venules, whereas no significant LEl were observed in pial arterioles or in sham-operated mice. With a delay of $>4 \mathrm{~h}$, leukocytes and aggregates did also firmly adhere to the venular endothelium. In deep cortical vessels $(250 \mu \mathrm{m}) \mathrm{LEls}$ were much less pronounced. Transmigration of leukocytes into the brain parenchyma only became significant after the tissue became necrotic. Treatment with anti-CD18 antibodies reduced adhesion by 65\%; however, this treatment had no effect on secondary lesion expansion.

Conclusions: LEl occurred primarily in pial venules, whereas little or no LEl occurred in arterioles or deep cortical vessels. Inhibiting LEI did not affect secondary lesion expansion. Importantly, the majority of migrating leukocytes entered the injured brain parenchyma only after the tissue became necrotic. Our results therefore suggest that neither intravascular leukocyte adhesion nor the migration of leukocytes into cerebral tissue play a significant role in the development of secondary lesion expansion following TBI.
\end{abstract}

Keywords: Leukocytes, Inflammation, Brain trauma, Secondary brain damage, Leukocyte adhesion, Leukocyteplatelet aggregates, 2-photon microscopy, Intravital microscopy, In vivo, Mice

\footnotetext{
* Correspondence: nikolaus.plesnila@med.uni-muenchen.de

${ }^{1}$ Institute for Surgical Research in the Walter-Brendel-Centre of Experimental

Medicine, University of Munich Medical Center, Marchioninistr. 15, 81377

Munich, Germany

${ }^{2}$ Department of Neurodegeneration, Royal College of Surgeons in Ireland

(RCSI), 123 St. Stephen's Green, Dublin 2, Ireland

Full list of author information is available at the end of the article
} 


\section{Introduction}

Leukocytes are believed to play an important role in secondary brain damage following acute brain injury such as stroke or brain trauma [1]. Following brain injury, blood-borne leukocytes begin to roll on - and subsequently stick to - the cerebrovascular endothelium, and then finally migrate into the cerebral tissue, where they are believed to cause damage, e.g. by releasing reactive oxygen species [2]. Inhibiting the adhesion of leukocytes to the endothelium (for example, by blocking intercellular adhesion molecule 1 (ICAM-1) or MAC-1), resulted in a significant reduction in infarct volume in experimental models of focal and global cerebral ischemia [3-7].

A similar sequence of events also seems to occur following traumatic brain injury (TBI); however, the role of leukocyte invasion in secondary brain damage remains somewhat controversial. Several reports support a contributing role of leukocytes in secondary brain damage. For example, an accumulation of polymorphonuclear leukocytes in the brain correlated with increased intracranial pressure (ICP) and reduced cerebral blood flow (CBF) following cold injury in rats [8]. Antibodies directed against leukocyte adhesion molecules (for example, anti-ICAM-1) reduced leukocyte accumulation in the tissue and led to improved neurological function following fluid percussion injury (FPI) [9]. Mice deficient in $\mathrm{T}$ and $\mathrm{B}$ cells and mice that were treated with $\mathrm{T}$ cell inhibitory agents had less traumatic brain damage following aseptic cerebral injury (ACI) than controls [10]. A 50\% reduction in total post-FPI contusion volume was correlated with a reduction in the number of accumulating monocytes/macrophages in the medial cortex three days after injury [11]. Finally, neutrophil depletion reduced CCI-induced edema formation and contusion volume in mice [12].

On the other hand, several studies have reported that neither inhibiting leukocyte adhesion with anti-CD18 antibodies nor depleting neutrophils affected the permeability of the blood-brain barrier (BBB) following experimental TBI [13-15], and mice that were deficient in Pselectin and ICAM-1 exhibited neuroprotection without a change in leukocyte accumulation [16]. Additionally, most studies regarding the role of leukocytes in posttraumatic brain damage did not investigate intravascular leukocyte accumulation, nor did they correlate the spatial and temporal accumulation of leukocytes in traumatized brain tissue. Accordingly, it remains unclear whether leukocytes adhere to the cerebrovascular endothelium, migrate into damaged tissue, and cause additional damage or whether they migrate into the damaged brain tissue only after secondary brain injury has occurred. To address these questions, we investigated both the time course and the effect on secondary contusion growth of a) leukocytes that accumulate in the tissue, and b) intravascular leukocytes and leukocyte-platelet aggregates that adhere to the cerebrovascular endothelium following traumatic brain injury precisely in the region in which secondary brain damage occurs.

\section{Material and methods}

\section{Animals}

For this study, we used 6 to 8 -week-old male C57Bl6 mice ( 23 to $26 \mathrm{~g}$ ) that were obtained from either Charles River (Kisslegg, Germany) or Jackson Laboratories (Bicester, UK). The animals had free access to tap water and pellet food. Mice that were allowed to awaken between subsequent procedures within one experiment were housed individually throughout the experiment. All animal experiments were conducted in accordance with institutional guidelines and approved by the government of Upper Bavaria (license number and ethical approval number 06/04), and by both the Ministry for Health and Children in Dublin, Ireland (license number B100/4169) and the Research Ethics Committee of the Royal College of Surgeons (REC number 467).

\section{Controlled cortical impact}

Traumatic brain injury was induced in a large craniotomy window over the right hemisphere using a controlled cortical impact (CCI) device that was optimized for use in mice $[17,18]$. For experiments involving intravital microscopy or histological assessment, the impact piston travelled at 6.0 or $8 \mathrm{~m} / \mathrm{s}$, respectively, with a penetration depth of 0.5 or $1.0 \mathrm{~mm}$, respectively; the contact time with the tissue was $150 \mathrm{~ms}$. Thereafter, the cranial bone was re-implanted and affixed with histoacrylic glue. Sham-operated animals were subjected to the same surgical procedure without the induction of a trauma.

\section{Experimental protocol for intravital microscopy monitoring}

These experiments were performed as previously described [18-20]. In brief, animals were anesthetized by an intra-peritoneal injection of medetomidine $(0.5 \mathrm{mg} / \mathrm{kg}$, Domitor $\left.^{\mathbb{B}}\right)$, fentanyl $(0.05 \mathrm{mg} / \mathrm{kg})$, and midazolam $\left(5 \mathrm{mg} / \mathrm{kg}\right.$, Dormicum $\left.{ }^{\circledR}\right)$. Following induction, the mice were endotracheally intubated and ventilated using a volume-controlled ventilator. Body temperature, endtidal $\mathrm{CO}_{2}$ and invasive systolic blood pressure were monitored continuously.

Subsequently, the animals were immobilized in a stereotactic frame, and two cranial windows - one for TBI and one for IVM monitoring - were prepared over the right hemisphere. After two baseline recordings of selected cerebral arterioles and venules, the animals 
were subjected to either TBI or a sham operation ( $\mathrm{n}=6$ mice per group); the animals were then transferred back to the intravital microscope, and the previously observed vessels were re-monitored 30,60, 90, and $120 \mathrm{~min}$ after CCI (Figure 1A + B). To monitor LEI at later time points $(4$ to $5.5 \mathrm{~h}, 8$ to $9.5 \mathrm{~h}$, and 12 to $13.5 \mathrm{~h}$ post-CCI; $\mathrm{n}=6$ animals per time point) mice were anesthetized with $2 \%$ isofluorane in $65 \% \mathrm{~N}_{2} \mathrm{O}$ and $33 \% \mathrm{O}_{2}$ and subjected to $\mathrm{CCI}$ as described above. Subsequently, the animals were allowed to awaken in a recovery chamber (heated to $33^{\circ} \mathrm{C}$ and containing $50 \%$ humidity). Upon the recovery of motor function, the mice were transferred to their respective cages. After 3, 7, or $11 \mathrm{~h}$, the animals were prepared for in vivo imaging as described above, and vessels were observed four times every $30 \mathrm{~min}$ (see
Figure 1C). At the end of each experiment, the animals were sacrificed by transcardiac perfusion with $4 \%$ PFA.

\section{Intravital microscopy of superficial vessels}

A square $(2 \mathrm{~mm} \times 2 \mathrm{~mm})$ cranial window was prepared over the right fronto-parietal cortex; the dura mater was kept intact. The cerebral microcirculation was then investigated in an area 1.5 to $3.5 \mathrm{~mm}$ frontal to the primary contusion (Figure 1A), that is, in the region in which secondary brain damage occurs $[18,21]$. The animals were placed on a computer-controlled microscope stage for repeated analyses of the same vessels. Visualization of the microvessels was facilitated by an intravenous injection of fluorescein isothiocyanatelabeled dextran (FITC-dextran; $0.1 \mathrm{ml}$ of a $0.5 \%$ solution;

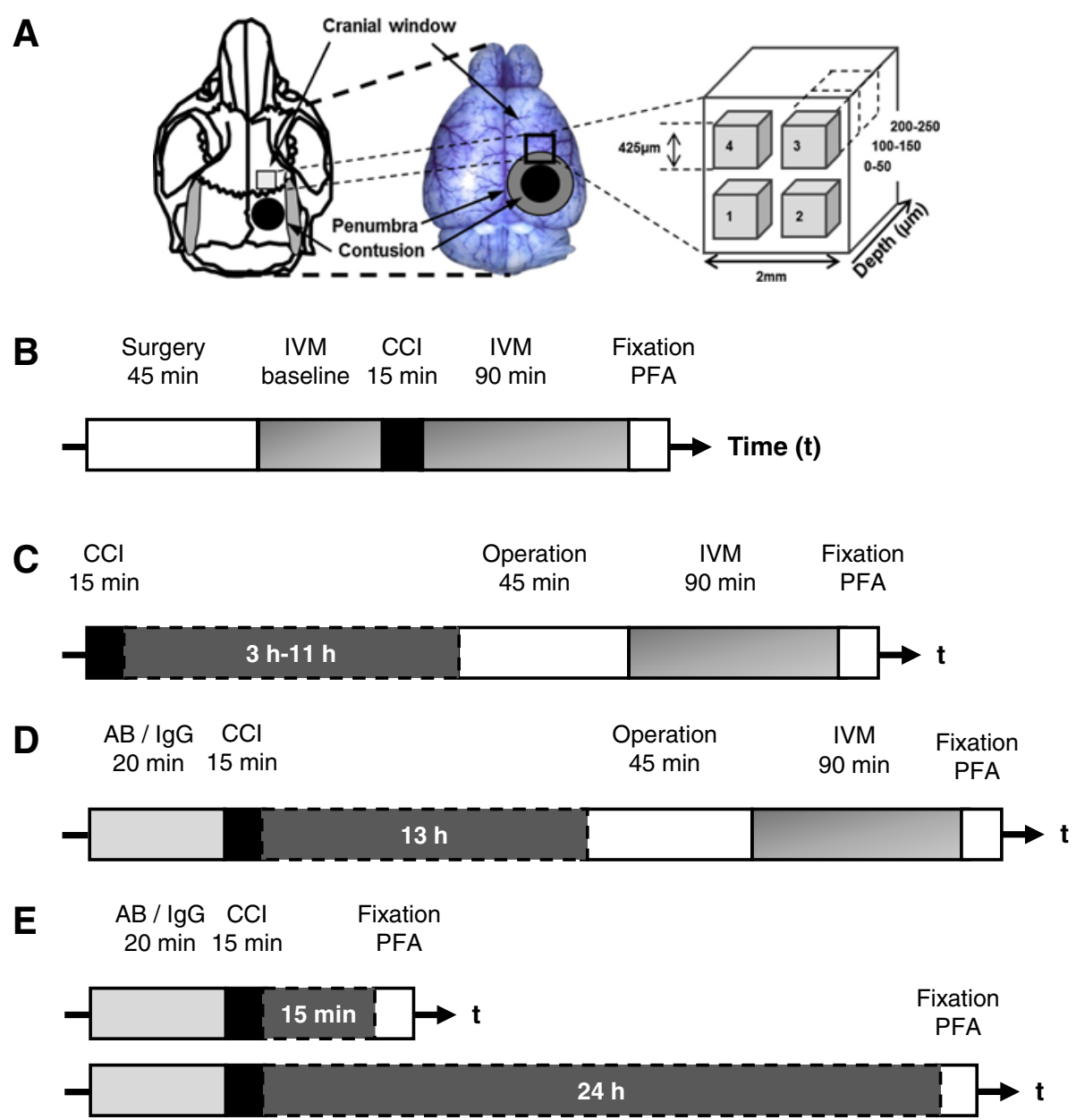

Figure 1 Experimental design. (A) Schematic illustration of the imaging window and controlled cortical impact (CCl)-induced contusion and penumbra sites. (B) Timeline of the experiments for monitoring the cerebral microcirculation, including baseline recording. (C) For observations up to $14 \mathrm{~h}$ post-trauma, the mice were allowed to recover in their respective cages until the preparation for intravital microscopy (IVM). (D) Following an injection of either anti-CD18 antibodies or control IgG, the animals were subjected to CCl; $13 \mathrm{~h}$ thereafter, the mice were prepared for IVM. All IVM experiments ended with perfusion-fixation with paraformaldehyde and the subsequent removal of the brain. (E) The animals received either control IgG or anti-CD18 antibodies and were then subjected to $\mathrm{CCl}$; $15 \mathrm{~min}$ or $24 \mathrm{~h}$ later, their brains were removed for histological assessment. 
molecular weight 150,000; Sigma Chemical, St. Louis, Missouri, USA). Before each measurement, leukocytes were stained by repeated intravenous injections of the fluorescent dye rhodamine $6 \mathrm{G}(0.05 \mathrm{ml}$ of a $0.01 \%$ solution; Merck, Darmstadt, Germany). The images were collected using a video camera and recorded on videotape.

\section{Analysis of leukocyte-endothelium interactions in pial vessels}

A computer-assisted microcirculation analysis system (CapImage; Ingenieurbüro Dr. Zeintl, Heidelberg, Germany) was used to quantify the IVM images off line by a frame-to-frame analysis [18]. The number of rolling and adherent leukocytes (7 to $12 \mu \mathrm{m}$ in size) and aggregates (15 to $25 \mu \mathrm{m}$ in size) was analyzed in the arterioles and venules by an investigator who was blinded with respect to the treatment of the animals. For each region of interest, a vessel segment $50 \mu \mathrm{m}$ in length was studied for $30 \mathrm{sec}$ in each measurement.

Rolling leukocytes/aggregates were identified by multiple intermittent contacts with the vascular endothelium and by their significantly lower velocity compared to freely moving leukocytes/aggregates in the central flow of the vessel. Leukocytes/aggregates were categorized as adherent when they attached firmly to the vascular endothelium for longer than $30 \mathrm{sec}$.

\section{Intravital microscopy of vessels in deeper regions of the brain}

To investigate LEI in deeper regions of the brain (that is, at a depth of 50,150 , and $250 \mu \mathrm{m}$ ), we used a Zeiss 2photon imaging system that was based on an LSM 710 confocal microscope equipped with a Chameleon Vision II Ti:Sa laser (Coherent Scotland Limited, West of Scotland Science Park, Glasgow, Scotland). The principle of multi-photon microscopy implies that there is only one point where the excitation photons meet and thus result in an excitation of the dye. The great advantage of this technique is that this point can be at any chosen level within several $100 \mu \mathrm{m}$ depths in the tissue. The emitted light will always come from this one point and can be detected with high spatial accuracy [22]. The animals were subjected to CCI and prepared for in vivo imaging as described above. For 2-photon imaging, a $2 \mathrm{~mm} \times 2 \mathrm{~mm}$ craniotomy window was prepared under continuous cooling with saline, the dura mater was carefully removed, and a custom-made cover glass (Schott Displayglas, Jena, Germany) was inserted and affixed with dental cement (Cyano Veneer, Hager \& Werken, Duisburg, Germany).

Eight to ten hours after CCI, animals were transferred to the 2-photon microscope and IVM was performed according to a standardized protocol. The cranial window was divided equally into four parts, each containing one region of interest (ROI). In total, we monitored 12 regions (that is, four ROIs at three different depths). Each ROI covered a volume of $425 \mu \mathrm{m} \times$ $425 \mu \mathrm{m} \times 50 \mu \mathrm{m}$, and the layers covered 0 to $50 \mu \mathrm{m}, 100$ to $150 \mu \mathrm{m}$, and 200 to $250 \mu \mathrm{m}$ below the surface see Figure 1A. Z-stacks were acquired in $2-\mu \mathrm{m}$ steps within 30 sec. For each ROI, two consecutive z-stacks were acquired. Vessels, leukocytes, and leukocyte-platelet aggregates were labeled as described above. We used an excitation wavelength of $830 \mathrm{~nm}$ and detected green and red fluorescence using two non-descanned detectors (NDD; BP500-550 and BP565-610).

\section{Analysis of leukocyte-endothelium interaction in deep vessels}

The data were analyzed using ImageJ (downloaded from http://imagej.nih.gov/ij/) using the plugins Calculator Plus, Co-localization, and $3 D$ Object Counter. Leukocytes and leukocyte-platelet aggregates were identified according to their respective sizes as described above. By acquiring two consecutive images within $60 \mathrm{sec}$, we were able to identify leukocytes and aggregates as being either rolling or adherent.

\section{Contusion volume}

The animals were deeply anesthetized with $4 \%$ isofluorane in $33 \% \mathrm{O}_{2}$ and $63 \% \mathrm{~N}_{2} \mathrm{O}$ and sacrificed by cervical dislocation $15 \mathrm{~min}$ or $2,6,12$, or $24 \mathrm{~h}$ after CCI. Subsequently, the brain was removed, snap-frozen on powdered dry ice, and stored at $-80^{\circ} \mathrm{C}$. Coronal sections (10- $\mu \mathrm{m}$ thick) were collected every $500 \mu \mathrm{m}$ through the entire brain using a cryostat, stained with cresyl violet, and digitally recorded. The area of the contusion and of both hemispheres was quantified using an image analysis system (Olympus DP-SOFT; Olympus, Hamburg, Germany) by an investigator who was blinded with respect to the treatment conditions. Compared to healthy tissue the nuclei in the contusion are pyknotic and densely stained and the neuropil is very pale [21,23,24].

The size of the necrotic areas was corrected for brain swelling, and total contusion volume was calculated based on the contusion areas that were obtained from 15 sections $[17,21]$.

\section{Immunohistochemistry}

Staining was performed on frozen or paraffin-embedded tissues as described previously [25]. Paraffin sections were used to detect CD45-positive leukocytes and CD5 positive $\mathrm{T}$ lymphocytes; frozen sections were stained for the detection of Ly6G-positive granulocytes and monocytes, CD19-positive B lymphocytes and CD3e-or TCRß- positive $\mathrm{T}$ lymphocytes. Before staining, the sections were fixed in methanol then air-dried, after 
which endogenous peroxidase activity was blocked with $3 \% \mathrm{H}_{2} \mathrm{O}_{2}$ for $10 \mathrm{~min}$. To label the leukocyte subpopulations, we used the following primary and secondary (horseradish peroxidase-conjugated) antibodies (all from BD Biosciences Pharmingen, California, USA): rat-anti-mouse-CD45 (Ly-5) antibody (1:50) followed by goat-anti-rat antibody (1:50); rat-anti-mouse-Ly6G and Ly6C (Gr-1) antibody (1:100) followed by goat-anti-rat antibody (1:50); rat-anti-mouse-CD19 antibody (1:500) followed by goat-anti-rat antibody (1:50); hamster-antimouse-CD3 $\varepsilon$ antibody (1:100) followed by goat-antihamster antibody (1:50); rat-anti-mouse-CD5 (Ly-1) antibody (1:50) followed by goat-anti-rat antibody (1:50); or hamster-anti-mouse-TCRß-chain antibody (1:3000) followed by mouse-anti-hamster antibody (1:50). The sections were incubated for 60 and $30 \mathrm{~min}$ with the primary and secondary antibodies, respectively. Between each step, the sections were rinsed twice for $10 \mathrm{~min}$ with PBS. Staining was visualized using a DAB detection kit according to the manufacturer's instructions (VectorLabs, Burlingame, CA, USA). The nuclei were counter-stained with methylene blue. For positive controls, we used splenic tissue; for negative controls, some sections were not incubated with the primary antibody.

The section that was selected for quantification was the section that contained the largest contusion among 15 coronal sections that were cut through the contused brain. Leukocytes were quantified by counting all of the labeled cells in the injured and uninjured hemispheres. The analysis was performed by an investigator who was blinded with respect to the treatment of the animals. To assess post-trauma leukocyte accumulation in the brain, 48 animals were randomly assigned to the following six groups: $15 \mathrm{~min}$ and 2, 6, 12, 24, and $48 \mathrm{~h}$ following CCI. For each time point, paraffin and frozen sections were prepared from four animals.

\section{Inhibition of leukocyte adherence using anti-CD18 antibodies}

Animals were anesthetized with $2 \%$ isofluorane in $65 \%$ $\mathrm{N}_{2} \mathrm{O}$ and $33 \% \mathrm{O}_{2}$, then received $1.2 \mu \mathrm{g} / \mathrm{g}$ bodyweight of either an antibody directed against CD18 (GAME-46, BD Biosciences Pharmingen, California, USA) or a control IgG delivered via the femoral vein [26]. Subsequently, the animals were subjected to CCI as described above. To investigate the antibody's effect on LEI, we performed IVM in both groups ( $\mathrm{n}=6$ mice per group) at 16 and $16.5 \mathrm{~h}$ post-injury as described above (Figure 1D). To detect the potential effect of anti-CD18 treatment on secondary brain damage, animals were sacrificed $15 \mathrm{~min}$ or $24 \mathrm{~h}$ post-injury ( $\mathrm{n}=7$ mice per group; Figure $1 \mathrm{E}$ ), and contusion volume was assessed by histomorphometry as described above.

\section{Statistical analysis}

Sample size was calculated before start of the study based on the following parameters: for the IVM experiments, a standard deviation of 25 to $30 \%$ of mean, a minimally detectable difference of at least $50 \%$, and a power of 0.8 ; for histological assessment, a standard deviation of $15 \%$, a minimally detectable difference of at least $25 \%$, and a power of 0.8 .

The Mann-Whitney $U$-test was used to analyze the differences between groups. The Friedman one-way analysis of variance on ranks followed by the StudentNewman-Keuls test was used to analyze differences over time. Data obtained from the histological analysis are presented as mean $+/$ - standard deviation (SD), and data acquired from the in vivo imaging experiments are presented as mean $+/-$ standard error of the mean (SEM), unless indicated otherwise. Differences with a $P$ value of $<0.05$ were considered to be statistically significant.

\section{Results}

Animal physiology

The blood gases, blood electrolytes, and physiological parameters (mean arterial blood pressure and core body temperature) of the animals were monitored and maintained within physiological limits throughout all experiments. Tables 1 and 2 show representative examples taken from two experimental groups. There were no significant differences between the groups or between different time points within an individual group for any physiological parameter.

Physiologically important parameters were monitored continuously throughout the experiments ( $n=7$ animals per group). End-tidal $\mathrm{pCO}_{2}$, mean arterial blood pressure $(\mathrm{MABP})$ and ventilation frequency were recorded throughout every IVM recording experiment included in this study. The parameters remained within the physiological range as shown in this representative table of values obtained in the experiments testing the effect of anti-CD18 antibodies or IgG control. None of the parameters showed a significant difference between groups.

At the end of each IVM recording experiment blood gases were analyzed. The $\mathrm{pH}, \mathrm{pCO}_{2}$ and $\mathrm{pO}_{2}$ remained within physiological thresholds and showed no significant difference between groups. The observed metabolic acidosis is not unusual for laboratory rodents fed with standard chow.

\section{Leukocyte-endothelium interactions in the superficial vessels 0 to 14 hours post-controlled cortical impact} Under normal physiological conditions, leukocyte rolling occurs at a rate of $8.1+/-0.4$ leukocytes $/ 100 \mu \mathrm{m} / \mathrm{min}$ as quantified in the venules of the sham-operated mice and 
Table 1 Physiological parameters of the animals at the indicated times during the experiments

\begin{tabular}{lccr}
\hline & $\mathbf{1 6}$ hours & $\mathbf{1 6 . 5}$ hours & Mean \\
\hline end-tidal pCO2 control IgG & $33.6+/-2.1$ & $32.8+/-1.9$ & $33.2+/-1.9$ \\
end-tidal pCO2 anti-CD18 AB & $32.8+/-1.2$ & $31.0+/-1.0$ & $31.9+/-1.1$ \\
MABP control IgG & $74.0+/-7.2$ & $69.6+/-3.4$ & $71.8+/-5.2$ \\
MABP anti-CD18 AB & $78.0+/-3.4$ & $71.0+/-4.0$ & $74.5+/-3.4$ \\
Ventilation f control lgG & $149+/-8.4$ & $144+/-8.3$ & $146.5+/-8.1$ \\
Ventilation $\mathrm{f}$ anti-CD18 AB & $141.6+/-8.8$ & $145.0+/-8.8$ & $143.3+/-8.5$ \\
\hline
\end{tabular}

under baseline conditions prior to TBI. No other leukocyte interactions were observed in the venules or arterioles (Figure 2A; Figure 3A,C). Within two hours of inducing trauma, the number of rolling leukocytes in the venules increased significantly to $25.7+/-5 / 100 \mu \mathrm{m} /$ $\min (P<0.01$ versus baseline and sham; Figure $2 \mathrm{~B}$; Figure $3 \mathrm{~A})$. This enhanced level of LEI was stable until the end of the observation time, that is, $13.5 \mathrm{~h}$ after trauma $(P<0.001$ versus baseline and sham; Figure 3A).

The increase in the number of adherent leukocytes in the venules only reached significance $4 \mathrm{~h}$ following CCI $(5+/-2.1$ adherent leukocytes $/ 100 \mu \mathrm{m} / \mathrm{min})$, which was an increase of approximately ten-fold over baseline $(P<$ 0.02 versus baseline and sham). After $8 \mathrm{~h}$, this number reached $17.5+/-3.2$ adherent leukocytes $/ 100 \mu \mathrm{m} / \mathrm{min}$, and this rate was stable until the end of observation time $(P<0.001$ versus baseline and sham; Figure 3C). In arterioles, neither rolling nor adherent leukocytes were present in noteworthy numbers.

We also observed the formation of leukocyte-platelet aggregates, which were defined by their size of 15 to $25 \mu \mathrm{m}$ [18]. No rolling or adherent aggregates were evident under baseline conditions in either the venules or arterioles (Figure 2A).

Following TBI, rolling aggregates appeared in the venules within the first two hours after injury (Figure $2 \mathrm{~B}$ ), although this did not reach significance $(P=0.053$ versus baseline and sham; Figure $3 \mathrm{~B}$ ). In contrast, at $4 \mathrm{~h}$ post-injury, the number of rolling aggregates had reached highly significant levels $(7.3+/-1.4$ rolling aggregates $/ 100 \mu \mathrm{m} / \mathrm{min} ; P<0.001$ versus baseline and sham). Finally, we measured $17.9+/-3.3$ rolling aggregates $/ 100 \mu \mathrm{m} / \mathrm{min}$ at $13.5 \mathrm{~h}$ post-injury; the number of rolling aggregates had not reached a plateau by the end of the observation time (Figure 3B).
Similar to adherent leukocytes, the number of adherent aggregates only became significant at $4 \mathrm{~h}$ post-CCI (1.6 +/ $-0.4 / 100 \mu \mathrm{m} / \mathrm{min} ; P<0.01$ versus baseline and sham). The number of adherent aggregates continued to increase over time without reaching a plateau $(13.3+/-$ 1.2 adherent aggregates $/ 100 \mu \mathrm{m} / \mathrm{min}$ at $13.5 \mathrm{~h}$ posttrauma; $P<0.001$ versus baseline and sham; Figure $3 \mathrm{D})$. We observed no rolling or adherent aggregates in the arterioles.

\section{Leukocyte-endothelium interactions at a depth of 0 to $\mathbf{2 5 0} \boldsymbol{\mu m} \mathbf{8} \mathrm{h}$ post-controlled cortical impact}

At depths of 0 to $50 \mu \mathrm{m}$ and 100 to $150 \mu \mathrm{m}$, there was a trend towards an increasing number of rolling leukocytes after trauma relative to sham-operated animals (Figure 4A-D; Figure 5A,B left graphs), which became significant in two ROIs. At a depth of 0 to $50 \mu \mathrm{m}$, in ROI 4 we counted $9.5+/-2$ rolling leukocytes after CCI compared to $4.7+/-1.1$ in the sham-operated animals $(P<0.02)$. At a depth of 100 to $150 \mu \mathrm{m}$, in ROI 3 we detected $7.7+/-0.9$ and $4.0+/-0.6$ rolling leukocytes after CCI and in sham-operated animals, respectively $(P<0.002)$. The average total intravascular volume in an ROI at a depth of 100 to $150 \mu \mathrm{m}$ was $17,300,000 \mu^{3}$ (Figure 5C left graph).

For all ROI at all depths, the number of adherent leukocytes was less than number of rolling leukocytes, and there were no significant differences between traumatized and sham-operated animals (Figure 5A-C left graphs).

We observed both rolling and adherent aggregates throughout all three levels; however, their numbers were smaller than the number of leukocytes, and there was no significant difference between animals that were

Table 2 Arterial blood gases

\begin{tabular}{lccc}
\hline & pH & pCO2 & pO2 \\
\hline Final arteriolar blood gas control lgG & $7.3+/-0.0$ & $39.1+/-2.6$ & $162.2+/-20.4$ \\
Final arteriolar blood gas anti-CD18 AB & $7.2+/-0.0$ & $44.3+/-3.2$ & $141.4+/-24.9$ \\
\hline
\end{tabular}



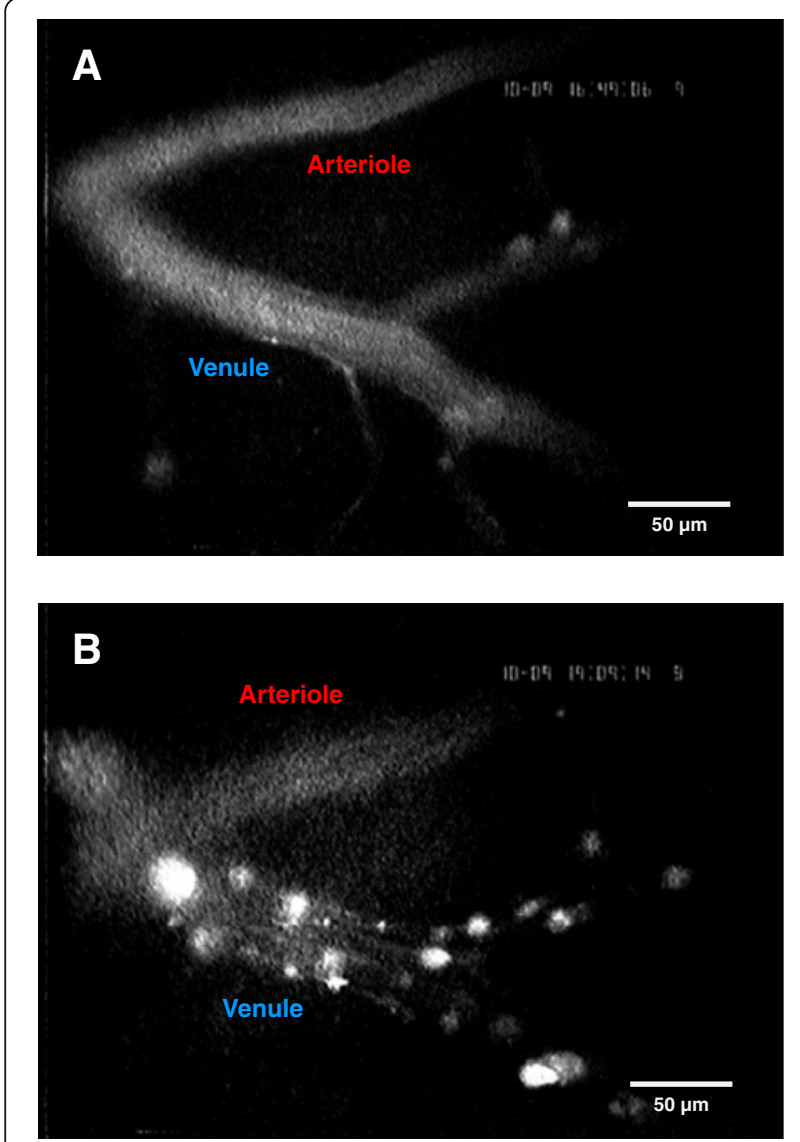

Figure $\mathbf{2}$ Representative images of superficial vessels. (A): A cerebral arteriole and a cerebral venule under baseline conditions. Neither adherent leukocytes nor a large number of rolling leukocytes are visible. (B): The same vessels as in A, $2 \mathrm{~h}$ after controlled cortical impact. Rolling and adherent leukocytes and aggregates are visible, predominantly in the venule.

subjected to $\mathrm{CCI}$ and sham-operated animals (Figure 5A-C right graphs).

\section{Leukocyte migration into the brain following traumatic brain injury quantified using immunohistochemistry Leukocytes}

The positive control (see Methods) exhibited staining inside the interfollicular spaces in the spleen. In contrast, we detected no labeled cells in either the negative control or in native brain slices. In the contralateral hemispheres of brains that were removed $24 \mathrm{~h}$ post-CCI, which served as controls, we counted $8+/-5$ leukocytes per hemisphere (Figure 6A, Figure 7B).

At every post-TBI observation time, we measured a significant increase in the number of leukocytes in the injured (ipsilateral) hemisphere relative to the amount in the contralateral side assessed at $24 \mathrm{~h}$ post injury $(P<0.03)$. At 24 and $48 \mathrm{~h}$ post-injury, a maximum of
$571+/-200$ leukocytes was reached in the ipsilateral hemisphere (Figure 6C, Figure 7B).

\section{$B$ lymphocytes}

In the positive controls, labeled cells were visible at the edge of the spleen's follicles, whereas both vaginae periarterialis lymphaticae and the red pulp were unlabeled. Neither the negative control nor the native brain sections contained any stained cells. No B lymphocytes were detected in the brain up to $48 \mathrm{~h}$ post-CCI.

\section{$T$ lymphocytes}

The positive controls exhibited staining of the vaginae periarterialis lymphaticae within the white pulp, whereas the peri-arteriolar spleen noduli and red pulp were unlabeled. Neither the negative control nor native brain sections contained any stained cells. No $T$ lymphocytes were detected in the brain up to $48 \mathrm{~h}$ post-CCI.

\section{Correlation between secondary brain injury and the migration of leukocytes into the brain}

Six hours after CCI, leukocytes were found primarily within the contusion, whereas very few leukocytes were present in the pericontusional penumbra (Figure 6). Both the contusion volume and the number of inflammatory cells in the traumatized hemisphere increased over time, reaching maximum values $24 \mathrm{~h}$ after injury (Figure $7 \mathrm{~B}+\mathrm{C}$ ). At all of the time points, the inflammatory cells were found predominantly at the center of the contusion (where the tissue was already necrotic), whereas virtually no inflammatory cells were found in the vulnerable penumbra, where the neurons were still alive (Figure 8A-D). This finding indicates that leukocytes accumulated in the tissue only after secondary lesion expansion had occurred. We did not detect any leukocytes in the contralateral hemisphere (Figure 6A; Figure 7B).

\section{Inhibition of leukocyte adherence using anti-CD18 antibodies}

In light of the above results, we investigated the effect of anti-CD18 antibodies on leukocyte adhesion in the venular endothelium at a time in which pronounced LEI occurred, that is, $16 \mathrm{~h}$ post-injury. Following the administration of an anti-CD18 antibody (control: IgG), we observed a significant reduction of leukocyte-endothelial interactions in pial microvessels (Figure 9A - D). Quantification of the data revealed no significant difference with respect to rolling leukocytes (Figure 10A). In contrast, the administration of anti-CD18 antibodies reduced the number of adherent leukocytes in the venules by approximately two-thirds the number in animals that received control IgG $(11.1+/-1.9$ versus 

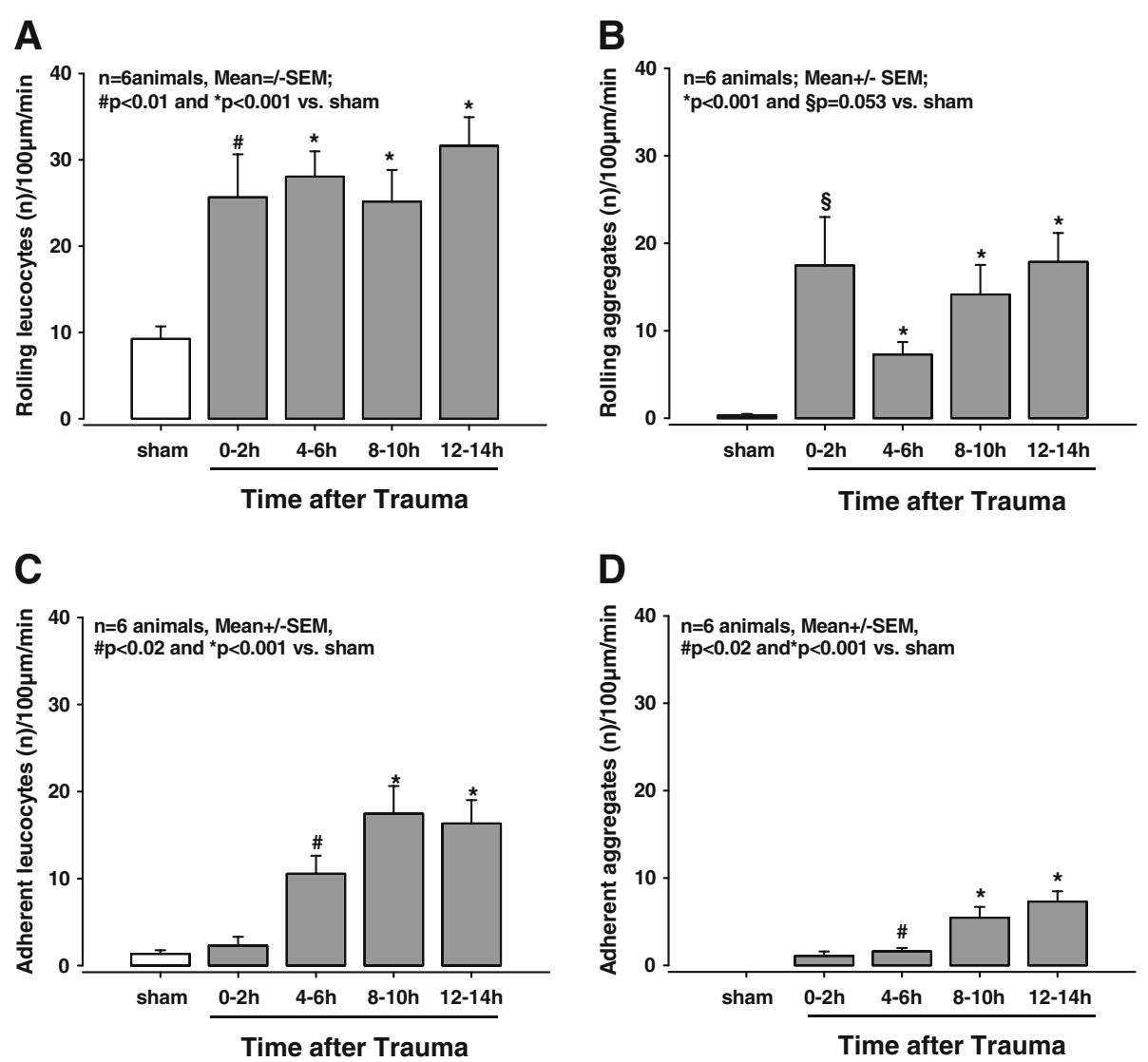

Figure 3 Quantification of leukocyte-endothelium interaction (LEI) in superficial vessels. (A- C) Number of rolling or adherent leukocytes in cerebral venules at the indicated times after controlled cortical impact (CCI). The number of rolling leukocytes was clearly increased immediately following $\mathrm{CCl}$. The number of adherent leukocytes reached significance after $4 \mathrm{~h}$. (B,D) The number of rolling and adherent aggregates in the cerebral venules after CCI showed a pattern similar to the leukocytes.

$33.7+/-7.9$ adherent leukocytes $/ 100 \mu \mathrm{m} / \mathrm{min}$, respectively; $P<0.01$; Figure 2C-F; Figure 10C).

Similar to the results for leukocytes, we observed no significant difference in rolling aggregates following the injection of either anti-CD18 antibody or control IgG (Figure 10B). However, the administration of anti-CD18 antibody reduced the number of adherent aggregates by two-thirds at $16 \mathrm{~h}$ post-CCI relative to the control IgG group (3.4 +/ -0.7 versus $9.0+/-1.9$ adherent aggregates/ $100 \mu \mathrm{m} / \mathrm{min}$, respectively; $P<0.02$; Figure $2 \mathrm{C}-\mathrm{F}$; Figure 10D).

\section{Contusion volume after injection of anti-CD18 antibody or control lgG}

Fifteen minutes post-CCI, contusion volume was $6.7+/-$ $1.3 \mathrm{~mm}^{3}$; this volume is equivalent to $13 \%$ of the total volume of the contralateral hemisphere. After $24 \mathrm{~h}$, secondary brain damage increased the contusion volume to $10.3+/-0.6 \mathrm{~mm}^{3}$ in mice that received control IgG (Figure 10E); a similar increase was observed in mice that received anti-CD18 antibody. $24 \mathrm{~h}$ following CCI mice in both groups had contusion volumes that were similar and equivalent to $16 \%$ of the volume of the contralateral hemisphere (Figure 10E).

\section{Discussion}

It is well known that TBI can induce an inflammatory reaction $[1,27,28]$; nevertheless, data supporting a role for blood-borne white blood cells as a causal factor in secondary brain injury following head trauma are highly controversial. There are many possible ways in which leukocytes could contribute to secondary brain damage, including the release of free radicals, the activation of proteases, the production of pro-inflammatory chemokines and cytokines, alterations in cerebral blood flow, and/or increases in vascular permeability [28-31]. These mechanisms could be mediated either via the interaction of leukocytes with the endothelium or via the leukocytes that migrate into the tissue. In the current study, we investigated both possibilities by visualizing leukocytes both in the intravascular space using in vivo microscopy and in brain tissue using 


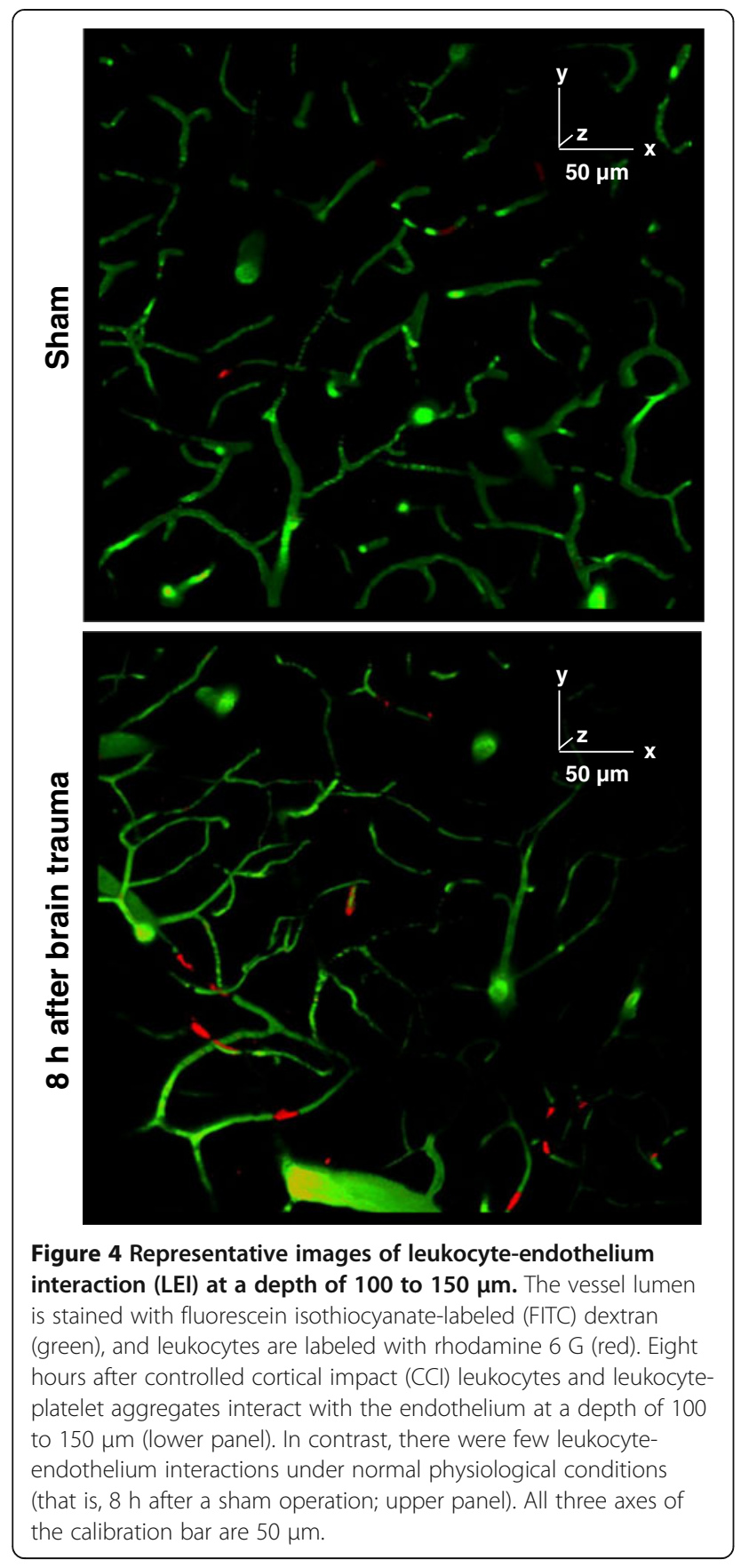

immunohistochemistry. Of note, all data were obtained from the traumatic penumbra, which is the area of the brain in which secondary brain damage occurs within the first $24 \mathrm{~h}$ following brain trauma [18,21,24,32]. Our results demonstrate that both increased LEI and the formation of leukocyte-platelet aggregates are initiated in the microcirculation of the penumbra within the first few hours following TBI. Nevertheless, these effects seem to occur predominantly in superficial vessels, and only to a much lower degree in deeper microvessels. Additionally, leukocytes migrate into the post-TBI brain only after the tissue becomes necrotic. The inhibition of LEI had no effect on secondary lesion expansion following CCI.

\section{Intravascular leukocyte-endothelium interactions in superficial vessels}

Using intravital microscopy, we investigated and quantified LEI up to $13.5 \mathrm{~h}$ following CCI. Under normal physiological conditions, LEI was limited to some rolling leukocytes in venules, which is in line with observations published previously by our group [19] and others [33]. Immediately following trauma, however, the number of rolling leukocytes increases significantly and - even more importantly - leukocytes begin to adhere to the venular endothelium. Most interestingly, these events occurred before secondary lesion expansion and hence could have potentially mediated secondary brain damage (for example, by disrupting the BBB or by initiating inflammatory cascades).

Elegant studies have suggested a correlation between post-trauma leukocyte accumulation in the brain and secondary brain damage $[11,12,29,34,35]$. However, in those studies, it was unclear whether the detrimental effect was caused exclusively by leukocyte accumulation or by an associated phenomenon such as leukocyte-endothelium adhesion initiating inflammatory cascades or an upregulation of the adhesion mediator ICAM- 1 and subsequent brain edema formation. Moreover, post-trauma ICAM-1 expression has been correlated with increased permeability of the BBB despite being independent of leukocyte accumulation in the brain [13-16,30,36]. In view of the possibility that ICAM-1 might play a leukocyteindependent role in secondary brain damage [2,31], we used an antibody directed against a structure located on the leukocytes themselves to directly investigate the role of intravascular LEI following TBI. Hence, we used an anti-CD18 antibody that is directed against the beta unit of the lymphocyte function-associated antigen 1 (LFA-1; $\beta$-chain CD18 and $\alpha$-chain CD11a), which binds to ICAM-1 and mediates (among other effects) leukocyte adhesion to the endothelium $[2,37,38]$. Thus, by blocking the interaction between LFA- 1 and ICAM-1, we inhibited leukocyte-endothelium interactions. Using this antibody, we reduced leukocyte adherence by approximately twothirds compared to an IgG control antibody. However, this did not affect the progression of secondary lesion expansion, indicating that leukocyte adherence to the cerebrovascular endothelium does not play an important role in the pathophysiology of secondary lesion expansion following CCI within the first $24 \mathrm{~h}$. We focused on leukocyte adherence, which has been shown to initiate intracellular signaling and disruption of the BBB $[2,39,40]$. In contrast, rolling leukocytes interact with the endothelium only very briefly and have not been assigned a role in 

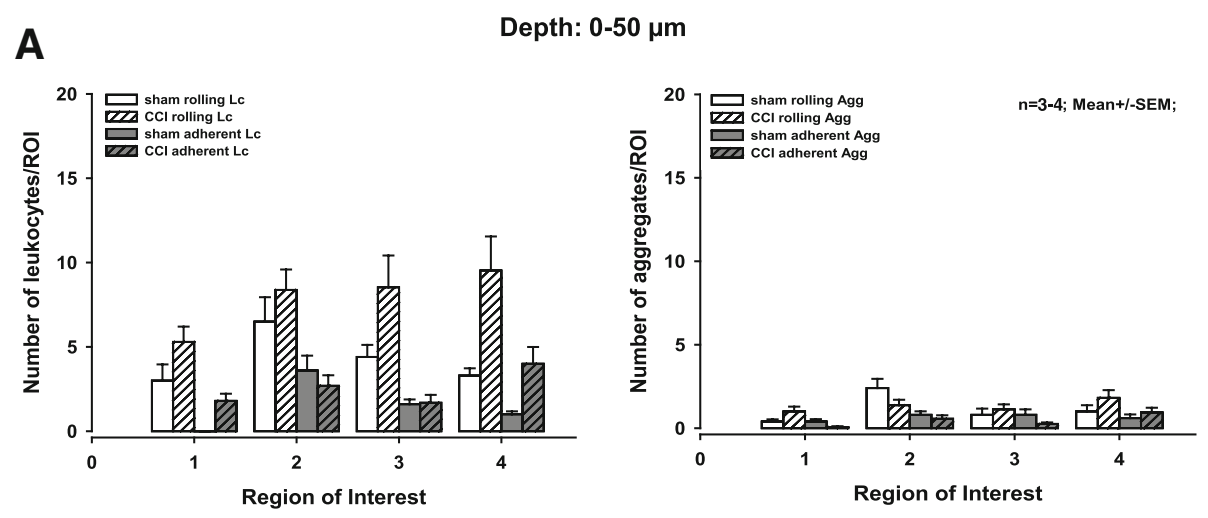

B

Depth: 100-150 $\mu \mathrm{m}$
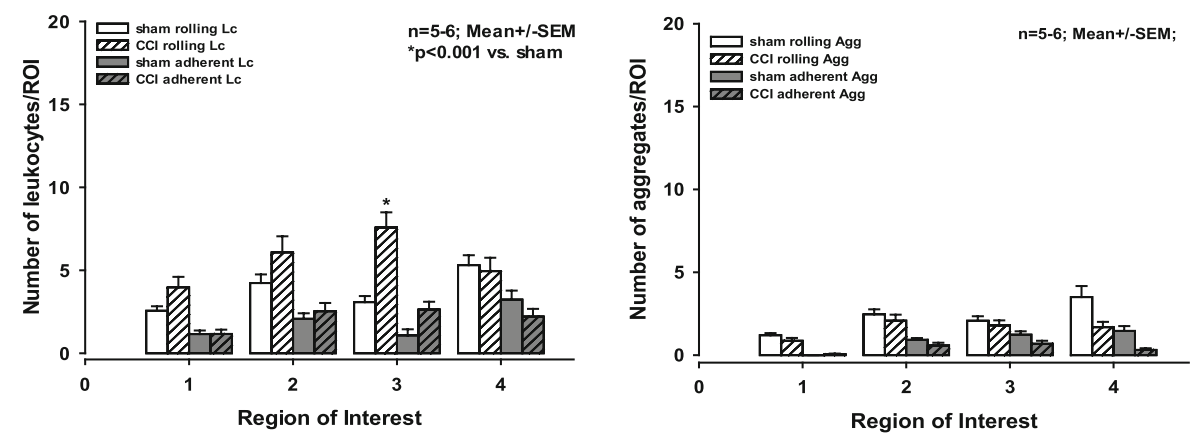

C

Depth: 200-250 $\mu \mathrm{m}$
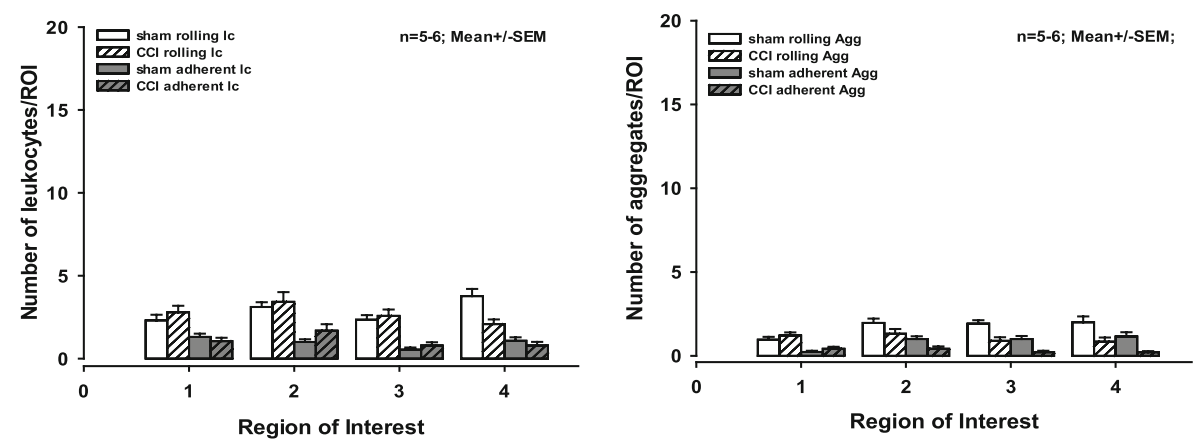

Figure 5 Quantification of leukocyte-endothelium interaction (LEI) at various depths. (A-C) Number of rolling and adherent leukocytes (left) and aggregates (right) at the indicated depths 8 to $10 \mathrm{~h}$ after controlled cortical impact (CCI). At each depth, LEl was measured in four standardized regions of interest (ROI). In ROI 4 at 0 to $50 \mu \mathrm{m}$ and in $\mathrm{ROI} 3$ at 100 to $150 \mu \mathrm{m}$, we observed significantly more rolling leukocytes than in sham-operated animals (A and B left, indicated with an asterisk). In all other ROls at all three depths, we observed no significant differences in LEl between $\mathrm{CCl}$ and sham-operated animals.

either initiating inflammatory cascades or opening the BBB.

\section{Effect of aggregates on secondary brain damage following traumatic brain injury}

To date, leukocyte-platelet aggregates have been reported to occur primarily in relation to endothelial stress, for example, due to increased levels of oxidized lipoprotein, inflammation, or diabetes [41-43]. Activated platelets up- regulate their expression of P-selectin, which then binds to its natural ligand, P-selectin-glycoprotein-ligand-1 (PSGL1 ), on neutrophils and monocytes [44].

Using intravital microscopy, the formation of leukocyte-platelet aggregates was observed both after subarachnoid hemorrhage (SAH) [45] and after TBI [18]. Following SAH, an antibody directed against Pselectin significantly reduced the formation of leukocyteplatelet aggregates and the adherence of aggregates to 


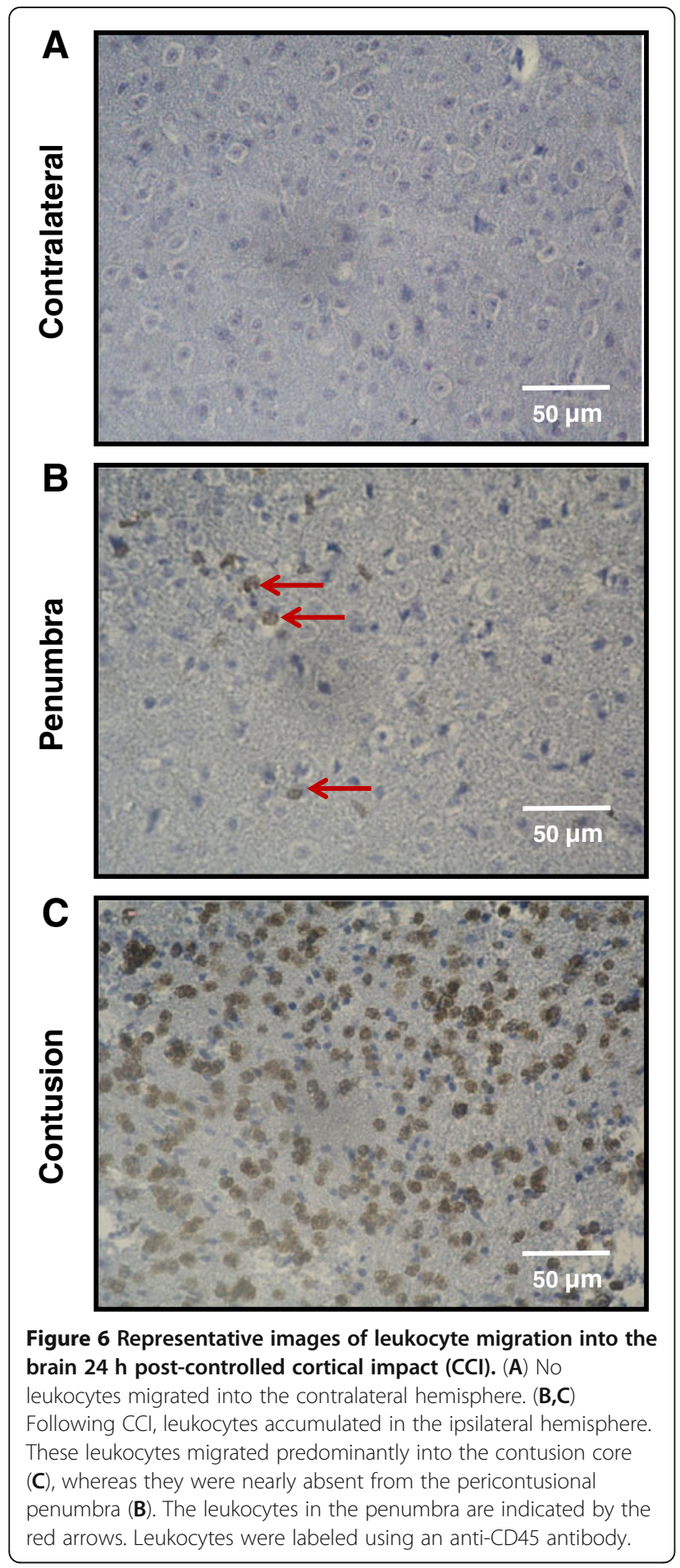

the endothelium [45]. Similarly, in our study, inhibiting leukocyte adherence to the endothelium led to a reduction in the adherence of aggregates, which confirms that the aggregates were composed-at least in part-by leukocytes. Nevertheless, unlike the effect of inhibiting P-selectin following SAH, inhibiting LEI did not affect
A

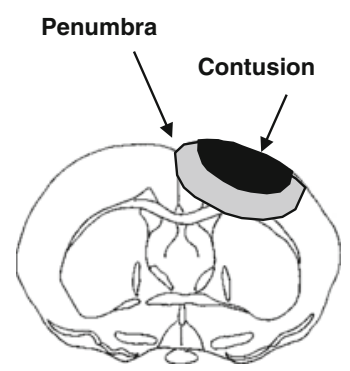

B

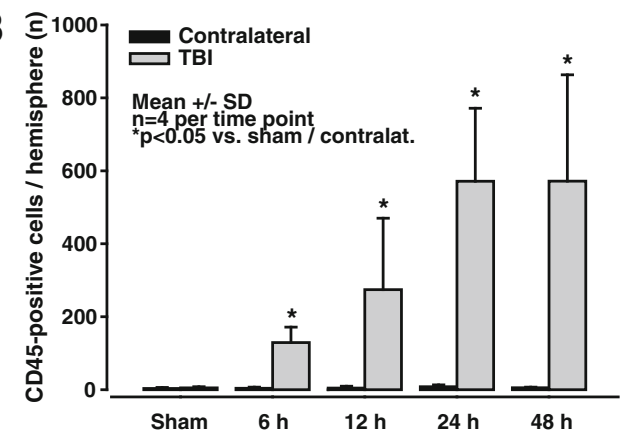

C

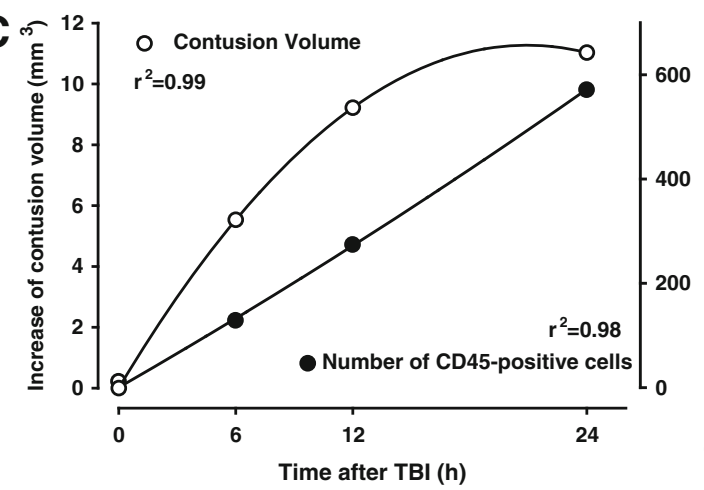

Figure $\mathbf{7}$ Leukocyte migration into the brain. (A) Schematic to illustrate the expansion of the secondary lesion. The contusion (black) is necrotic immediately after controlled cortical impact (CCI), and neuronal cell death occurs in the penumbra (gray) throughout the first 24 h. (B) Quantification of CD45-positive cells (that is, leukocytes) per hemisphere. The black columns indicate the numbers of leukocytes in the contralateral hemisphere $24 \mathrm{~h}$ after $\mathrm{CCl}$. Compared to the contralateral hemisphere, the number of leukocytes in the ipsilateral hemisphere (traumatic brain injury (TBI), gray columns) increased significantly over time, reaching the maximum value at $24 \mathrm{~h}$ post-CCl. (C) Time course of secondary lesion expansion (measured as necrotic tissue) and leukocyte accumulation in the tissue. The secondary growth of the cortical lesion (open circles) shows a shift to the left as compared to the time course of leukocyte invasion (closed circles). Accordingly, these data suggest that tissue dies first and leukocytes accumulate in the contusion thereafter.

aggregate formation itself. Because aggregates were observed almost exclusively in venules, their effect on the cerebral microcirculation - and in particular, their contribution to vessel occlusion - might not be of 


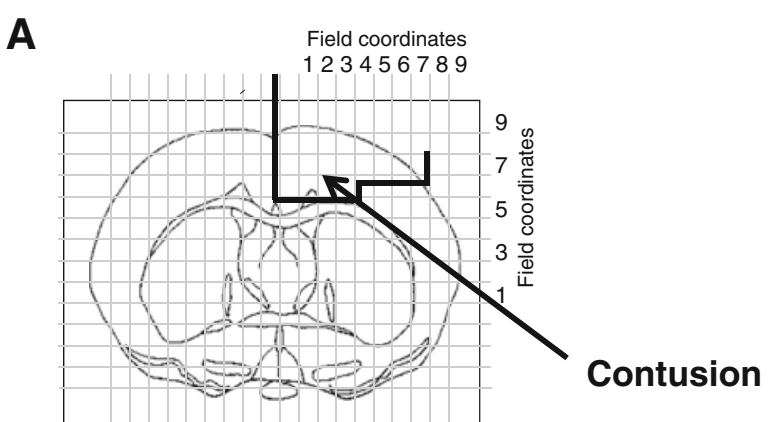

\section{B}

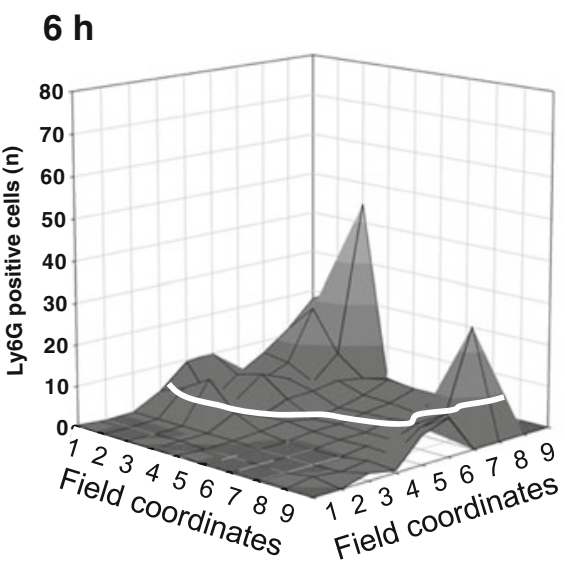

\section{$24 \mathrm{~h}$}

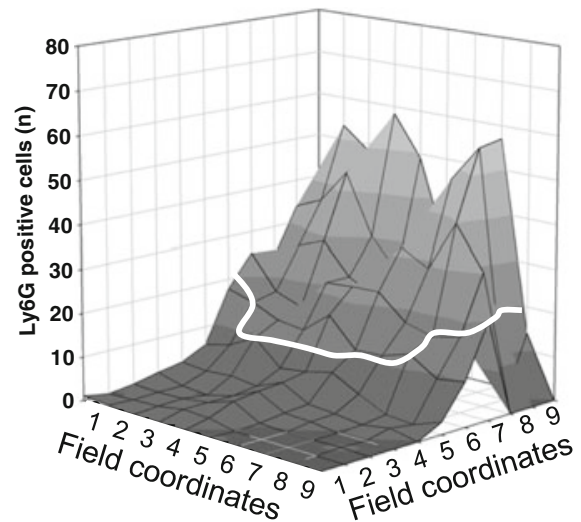

$12 \mathrm{~h}$

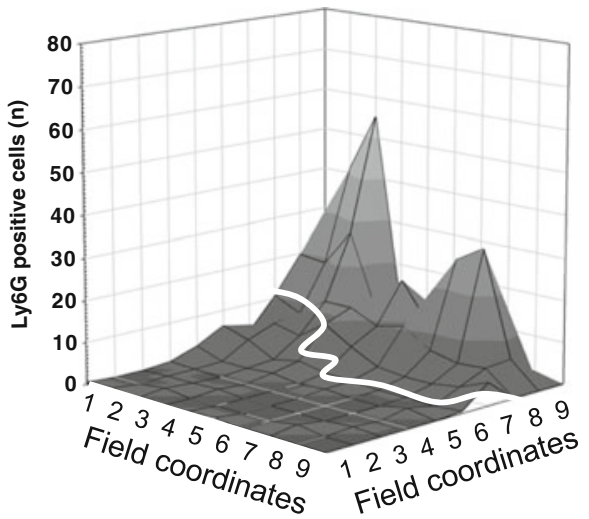

$48 \mathrm{~h}$

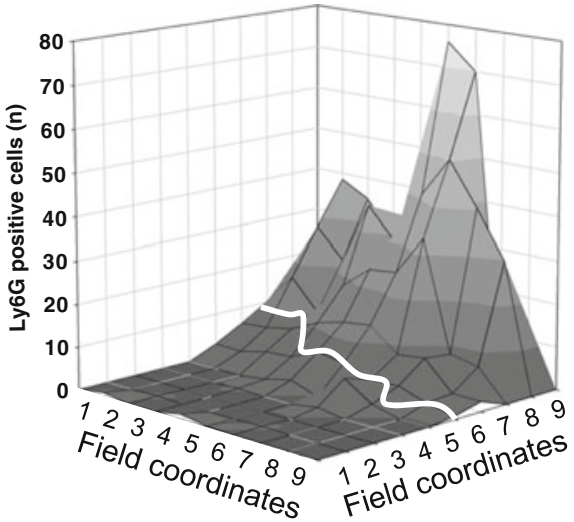

Figure 8 Post-trauma accumulation of Ly6G-positive granulocytes and monocytes. (A) Histological sections were divided into fields for the precise quantification of leukocytes in relation to the necrotic tissue in the contusion. In the figures in (B), the necrotic area is separated from the intact penumbra by the white line. The graphs illustrate the number of Ly6G-positive cells in each field at the indicated times following trauma. Leukocytes appeared in the brain only after neuronal cell death had occurred.

primary importance. However, post-TBI microvessel occlusions in tissues outside of the brain have been reported, for example, in the lung [46]. Despite the fact that the reduction of the adherence of aggregates to the venular endothelium did not affect secondary lesion expansion, it remains unclear whether directly inhibiting aggregate formation would have a beneficial systemic/ pulmonary effect following TBI. Accordingly, future studies of the role of P-selectin in aggregate formation and the role of post-trauma aggregates both in the brain and in other organs would be needed to clarify these questions. 

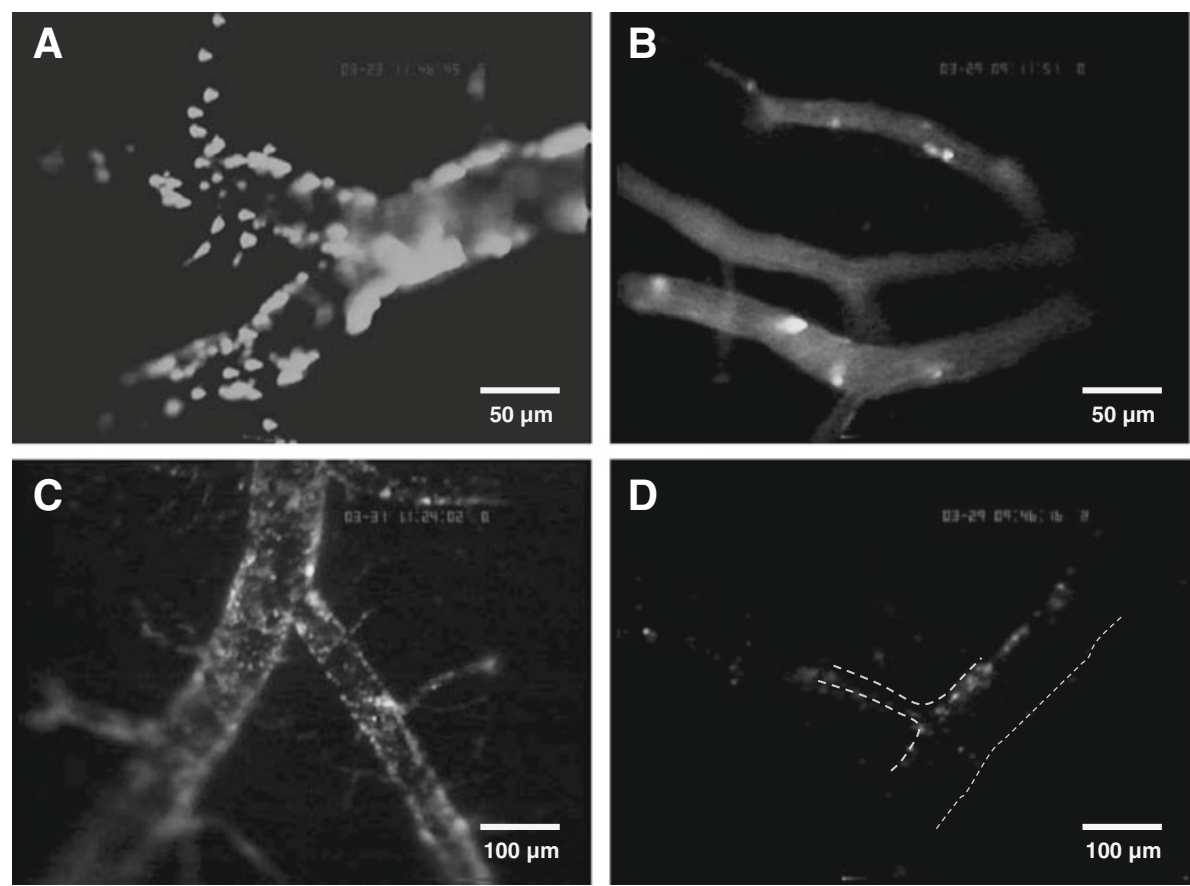

Figure 9 Representative images of superficial vessels in following administration of anti-CD18 antibodies or control IgG. (A,B) Rolling and particularly adhering leukocytes and aggregates in cerebral venules $14 \mathrm{~h}$ after controlled cortical impact. The animals received either control IgG (A) or anti-CD18 antibodies (B). (C,D) Cerebral microcirculation at lower magnification (note the difference in scale bases compared with A and B). The animals received either control $\lg G(\mathbf{C})$ or anti-CD18 antibodies (D). After administration of anti-CD18 antibodies the adherence of both leukocytes and aggregates to the venular endothelium was significantly reduced (B,D).

\section{Intravascular leukocytes and aggregates in deeper brain levels}

Although we also observed rolling and adherent leukocytes and aggregates at a depth of up to $250 \mu \mathrm{m}$ in the brain using 2-photon microscopy, these events were much less prevalent than in superficial vessels. This effect becomes even more prominent when the average vessel volume is taken into account. The vessel volume investigated in superficial venules (being approximately $85,500 \mu^{3}$ ) than in deeper regions of the brain $\left(492,100,173,200\right.$, and $125,800 \mu^{3}$ at depths of $0-50$, 100-150, and 200-250 $\mu \mathrm{m}$, respectively).

Several factors may account for this observation. First of all, the diameter of deep vessels (which are primarily capillaries with some arterioles and venules) is much smaller than the diameter of superficial venules. According to the Bernoulli and Venturi Law, a decrease in diameter is accompanied by an increase in blood flow velocity. Therefore, the much faster blood flow velocity in deeper vessels might reduce LEI by increasing shear stress and minimizing cellcell interactions. Secondly, the post-trauma inflammatory reaction is caused by the contusion itself and is therefore predominantly present in the vessels that drain blood from the site of injury. Hence, leukocyte activation and aggregate formation was scarcely present in arterioles but was present mainly in superficial venules and, to a limited degree, in deeper tissue, most likely in draining capillaries and postcapillary venules.

\section{Leukocyte migration into vulnerable tissue}

Our second aim was to investigate whether leukocytes accumulate in the region of interest (that is, the penumbra) before the tissue becomes necrotic. Because we quantified the expansion pattern of secondary brain damage surrounding the primary contusion at high temporal and spatial resolution $[17,21]$, we could compare the progression of neuronal cell death and leukocyte accumulation within the tissue over time. Following CCI, leukocytes accumulated predominantly in the contusion core. Although significant numbers of granulocytes and monocytes migrated into the tissue during the first $48 \mathrm{~h}$, neither $\mathrm{B}$ lymphocytes nor $\mathrm{T}$ lymphocytes appeared in the brain. The peak accumulation of leukocytes occurred at 24 to $48 \mathrm{~h}$ post-trauma, which is in agreement with previous studies, including a clinical report [47] and several animal experiments using either CCI $[15,48]$ or a weightdrop paradigm [48-50]. Other white blood cells such as monocytes, macrophages, $\mathrm{T}$ cells, and B cells appear predominantly 5 to 6 days after trauma [47,50,51], which is in agreement with our results. In contrast, 


\section{A}

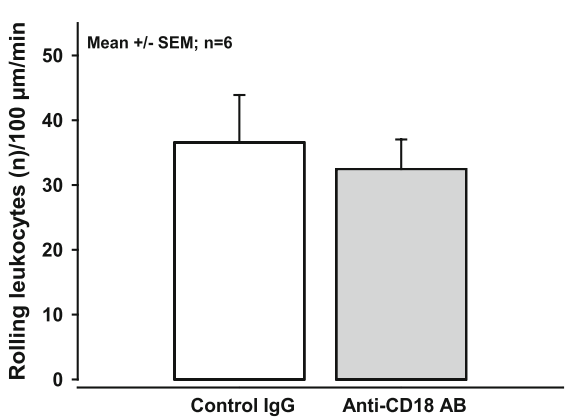

C

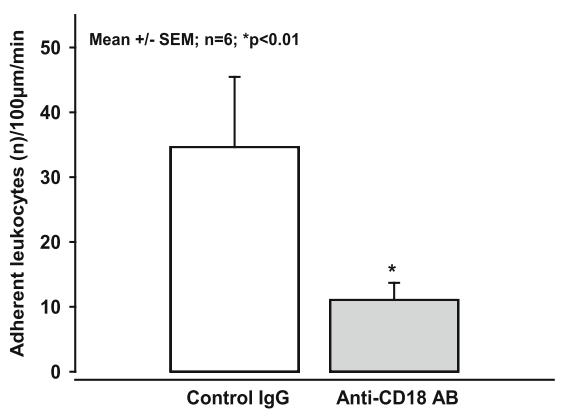

B

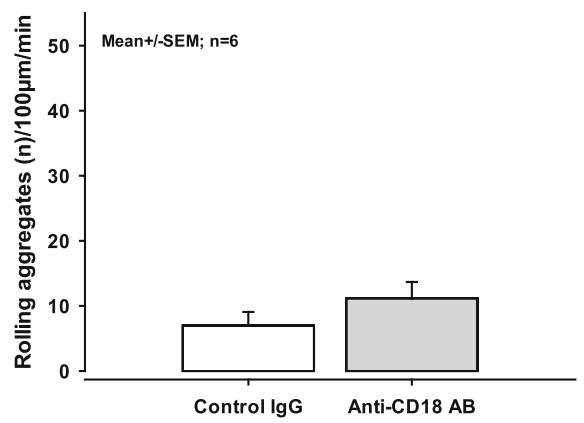

D

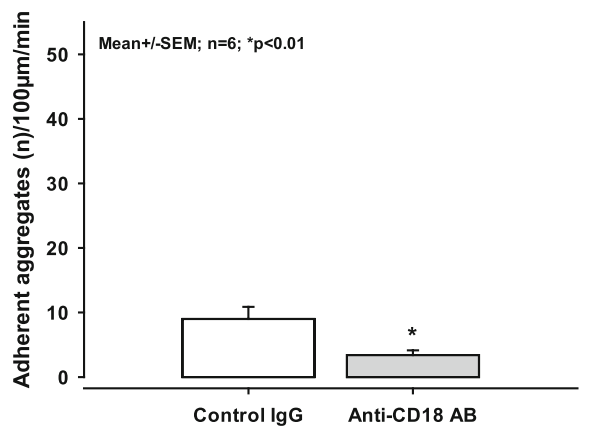

E

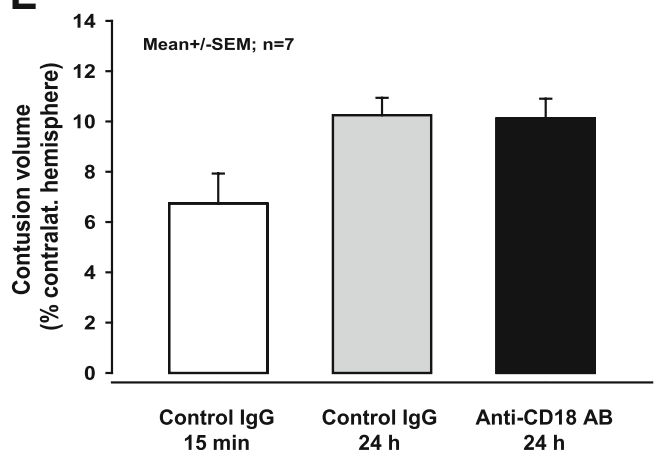

Figure 10 Effect of anti-CD18 antibodies on leukocyte-endothelium interaction (LEI) and contusion volume. (A) The number of rolling leukocytes in the cerebral venules $14 \mathrm{~h}$ after controlled cortical impact (CCI) was not affected by the administration of anti-CD18 antibodies compared to control IgG. (C) In contrast, the number of adherent leukocytes was reduced by approximately two-thirds by anti-CD18 antibodies relative to control lgG. (B,D) Qualitatively similar results were observed $14 \mathrm{~h}$ after $\mathrm{CCl}$ with respect to rolling and adhering aggregates in the cerebral venules after the administration of either anti-CD18 antibodies or control IgG. (E) Nevertheless, treatment with anti-CD18 antibodies had no effect on the expansion of the secondary lesion, measured $24 \mathrm{~h}$ after CCl.

Fee et al. reported the presence of activated CD4positive $\mathrm{T}$ cells at the site of traumatic injury within $24 \mathrm{~h}$ of aseptic cold injury (ACI) [10]. The authors described a clear correlation between CD4-positive T lymphocytes in the tissue and increased post-traumatic brain damage. This early accumulation of $\mathrm{T}$ cells is in contrast to both our results and results from Holmin et al. [50] and might be explained - at least in part - by the differences in the trauma models and experimental methods that were used in the respective studies.
In our experiments, leukocytes migrated into the tissue only after neuronal cell death had occurred; thus, their accumulation does not seem to play a role in secondary lesion growth following CCI.

\section{The role of leukocytes following controlled cortical impact versus other brain injury models}

Leukocyte-endothelium adherence and the subsequent migration of leukocytes are known to play a role in secondary brain injury following stroke. This role has 
been studied extensively, particularly with respect to LFA-1 and Mac-1, which both use the CD18 binding site $[6,52-54]$. The different result in our study can be most likely attributed to the post-injury differences in the pathophysiology that occur between stroke and TBI and by differences in the processes that are initiated selectively by the mechanical injury that results from CCI [55]. Despite some similarities in the progression of secondary brain damage following both types of injury, the relative importance of individual factors seems to differ. For example, the inflammatory response, including leukocyte-endothelium interactions, clearly plays a more important role in secondary brain injury following stroke than it plays in the wake of TBI $[1,55]$.

Another study reported that leukocyte infiltration into the tissue was correlated to histological outcome after fluid percussion injury (FPI) [11]. The accumulation of monocytes and macrophages within the brain was significantly reduced three days after FPI by the administration of anti-CD11 antibodies, which bind to a fraction of the CD11/CD18 integrin and thereby inhibit leukocyteendothelium adhesion; most importantly, this reduction in leukocyte accumulation was accompanied by a reduction in lesion volume. However, it remains unclear whether this beneficial effect was due to a reduction in either leukocyte adherence and/or leukocyte migration into the tissue. Again, this discrepancy with our results could be attributed primarily to differences in kinetics initiated by the different experimental models [56]. Firstly, FPI leads to diffuse brain injury that includes hemorrhagic contusions and reaches distant brain regions relative to the primary impact site [56-58]. In contrast, CCI produces a relatively restricted contusion with rapidly developing central necrosis $[56,59]$ in which the diffuse part [32] might be much less important. Hence, in TBI models that produce a much more extensive injury pattern (for example, CCI, in which the maximum lesion volume is reached within $24 \mathrm{~h}$ [17]), leukocytes may not contribute significantly to secondary lesion growth compared to models in which the initial injury is less severe and develops over longer periods of time (for example, FPI or ischemic brain injury). This is also supported by the finding that post-CCI leukocyte accumulation in the vulnerable tissue peaks at 24 to $48 \mathrm{~h}$ (as shown both in the current study and by others $[15,48])$, which is 1 to 2 days earlier than the time of peak leukocyte accumulation following FPI $[11,51]$.

\section{Summary}

Following CCI, leukocytes begin to migrate into the injured brain only after neuronal cell death has already occurred. Moreover, leukocytes accumulate predominantly in the contusion core (that is, in tissue that is already necrotic), but barely in the traumatic penumbra, where secondary injury occurs. Inhibiting the adhesion of leukocytes and aggregates to the cerebrovascular endothelium does not reduce the progression of secondary lesion growth. Consequently, our data suggest that blood-borne leukocytes do not mediate secondary lesion expansion following contusional TBI.

\section{Abbreviations \\ ACl: aseptic cerebral injury; ACI CBF: cerebral blood flow; BBB: blood-brain barrier; CCl: controlled cortical impact; CD: cluster of differentiation; FITC- dextran: fluorescein isothiocyanate-labeled dextran; FPI: fluid percussion injury; ICAM-1: intercellular adhesion molecule 1; ICP: intracranial pressure; G: immunoglobulin; IVM: intravital fluorescence microscopy; LEl: leukocyte- endothelium interaction; ROI: region of interest; $\mathrm{SAH}$ : subarachnoid hemorrhage; TBI: traumatic brain injury.}

\section{Competing interests}

The authors declare that they have no competing interests.

\section{Authors' contributions}

SMS helped designing the project, performed all experiments investigating $\mathrm{LEI}$ on the brain surface and the effect of anti-CD18 antibodies on secondary brain damage, analyzed and interpreted the data, provided assistance in designing and performing the experiments investigating deeper regions of the brain, and wrote the manuscript. RZ carried out all experiments determining post-trauma leukocyte accumulation in the tissue and the correlation with secondary brain damage, and analyzed and interpreted the data. NBMG performed all experiments to observe LEI in deeper brain regions and analyzed the data. RT provided assistance in designing and performing the experiments. SWK provided assistance in designing and performing the experiments. NP designed, coordinated and supervised the project, interpreted the data, edited and critically revised the manuscript. All authors read and approved the final manuscript.

\section{Author details}

${ }^{1}$ Institute for Surgical Research in the Walter-Brendel-Centre of Experimental Medicine, University of Munich Medical Center, Marchioninistr. 15, 81377 Munich, Germany. ${ }^{2}$ Department of Neurodegeneration, Royal College of Surgeons in Ireland (RCSI), 123 St. Stephen's Green, Dublin 2, Ireland. ${ }^{3}$ Institute for Stroke and Dementia Research (ISD), University of Munich Medical Center, Max-Lebsche Platz 30, 81377 Munich, Germany. ${ }^{4}$ Current address: Department of Anesthesiology, University of Munich Medical Center, Marchioninistr. 15, 81377 Munich, Germany.

Received: 1 August 2012 Accepted: 5 February 2013

Published: 28 February 2013

\section{References}

1. Feuerstein GZ, Wang X, Barone FC: Inflammatory gene expression in cerebral ischemia and trauma. Potential new therapeutic targets. Ann NY Acad Sci 1997, 825:179-193.

2. van Buul JD, Hordijk PL: Signaling in leukocyte transendothelial migration. Arterioscler Thromb Vasc Biol 2004, 24:824-833.

3. Chopp M, Zhang RL, Chen H, Li Y, Jiang N, Rusche JR: Postischemic administration of an anti-Mac-1 antibody reduces ischemic cell damage after transient middle cerebral artery occlusion in rats. Stroke 1994, 25:869-875.

4. Zhang RL, Chopp M, Li Y, Zaloga C, Jiang N, Jones ML, Miyasaka M, Ward PA: Anti-ICAM-1 antibody reduces ischemic cell damage after transient middle cerebral artery occlusion in the rat. Neurology 1994, 44:1747-1751.

5. Soriano SG, Lipton SA, Wang YF, Xiao M, Springer TA, Gutierrez-Ramos JC, Hickey PR: Intercellular adhesion molecule-1-deficient mice are less susceptible to cerebral ischemia-reperfusion injury. Ann Neurol 1996 39:618-624.

6. Soriano SG, Coxon A, Wang YF, Frosch MP, Lipton SA, Hickey PR, Mayadas TN: Mice deficient in Mac-1 (CD11b/CD18) are less susceptible to cerebral ischemia/reperfusion injury. Stroke 1999, 30:134-139. 
7. Scallan J, Huxley VH, Korthuis RJ: Capillary Fluid Exchange: Regulation, Functions, and Pathology. San Rafael (CA): Morgan \& Claypool Life Sciences; 2010.

8. Zhuang J, Shackford SR, Schmoker JD, Anderson ML: The association of leukocytes with secondary brain injury. J Trauma 1993, 35:415-422.

9. Knoblach SM, Faden Al: Administration of either anti-intercellular adhesion molecule-1 or a nonspecific control antibody improves recovery after traumatic brain injury in the rat. J Neurotrauma 2002, 19:1039-1050

10. Fee $D$, Crumbaugh A, Jacques $T$, Herdrich B, Sewell D, Auerbach D, Piaskowski S, Hart MN, Sandor M, Fabry Z: Activated/effector CD4+ T cells exacerbate acute damage in the central nervous system following traumatic injury. J Neuroimmunol 2003, 136:54-66.

11. Utagawa A, Bramlett HM, Daniels L, Lotocki G, Dekaban GA, Weaver LC, Dietrich WD: Transient blockage of the CD11d/CD18 integrin reduces contusion volume and macrophage infiltration after traumatic brain injury in rats. Brain Res 2008, 1207:155-163.

12. Kenne E, Erlandsson A, Lindbom L, Hillered L, Clausen F: Neutrophil depletion reduces edema formation and tissue loss following traumatic brain injury in mice. J Neuroinflammation 2012, 9:17

13. Hartl R, Medary M, Ruge M, Arfors KE, Ghajar J: Blood-brain barrier breakdown occurs early after traumatic brain injury and is not related to white blood cell adherence. Acta Neurochir Supp/ 1997, 70:240-242.

14. Hartl R, Medary MB, Ruge M, Arfors KE, Ghajar J: Early white blood cell dynamics after traumatic brain injury: effects on the cerebral microcirculation. JCereb Blood Flow Metab 1997, 17:1210-1220.

15. Whalen MJ, Carlos TM, Kochanek PM, Clark RS, Heineman S, Schiding JK, Franicola D, Memarzadeh F, Lo W, Marion DW, Dekosky ST: Neutrophils do not mediate blood-brain barrier permeability early after controlled cortical impact in rats. J Neurotrauma 1999, 16:583-594.

16. Whalen MJ, Carlos TM, Dixon CE, Robichaud P, Clark RS, Marion DW, Kochanek PM: Reduced brain edema after traumatic brain injury in mice deficient in P-selectin and intercellular adhesion molecule-1. J LeukocBiol 2000, 67:160-168.

17. Zweckberger K, Stoffel M, Baethmann A, Plesnila N: Effect of decompression craniotomy on increase of contusion volume and functional outcome after controlled cortical impact in mice. J Neurotrauma 2003, 20:1307-1314.

18. Schwarzmaier SM, Kim SW, Trabold R, Plesnila N: Temporal profile of thrombogenesis in the cerebral microcirculation after traumatic brain injury in mice. J Neurotrauma 2010, 27:121-130.

19. Kataoka H, Kim SW, Plesnila N: Leukocyte-endothelium interactions during permanent focal cerebral ischemia in mice. J Cereb Blood Flow Metab 2004, 24:668-676.

20. Thal SC, Plesnila N: Non-invasive intraoperative monitoring of blood pressure and arterial pCO2 during surgical anesthesia in mice. J Neurosci Methods 2007, 159:261-267.

21. Zweckberger K, Eros C, Zimmermann R, Kim SW, Engel D, Plesnila N: Effect of early and delayed decompressive craniectomy on secondary brain damage after controlled cortical impact in mice. J Neurotrauma 2006, 23:1083-1093.

22. Helmchen F, Denk W: Deep tissue two-photon microscopy. Nat Methods 2005, 2:932-940

23. Plesnila $N$, von Baumgarten $L$, Retiounskaia $M$, Engel $D$, Ardeshiri $A$, Zimmermann R, Hoffmann F, Landshamer S, Wagner E, Culmsee C: Delayed neuronal death after brain trauma involves p53-dependent inhibition of NF-kappaB transcriptional activity. Cell Death Differ 2007, 14:1529-1541.

24. Engel DC, Mies G, Terpolilli NA, Trabold R, Loch A, De Zeeuw Cl, Weber JT, Maas Al, Plesnila N: Changes of cerebral blood flow during the secondary expansion of a cortical contusion assessed by 14C-iodoantipyrine autoradiography in mice using a non-invasive protocol. J Neurotrauma 2008, 25:739-753.

25. Groger M, Lebesgue D, Pruneau D, Relton J, Kim SW, Nussberger J, Plesnila $\mathrm{N}$ : Release of bradykinin and expression of kinin B2 receptors in the brain: role for cell death and brain edema formation after focal cerebra ischemia in mice. J Cereb Blood Flow Metab 2005, 25:978-989.

26. Kunkel EJ, Dunne $J$, Ley K: Leukocyte arrest during cytokine-dependent inflammation in vivo. J Immunol 2000, 164:3301-3308.

27. Sahuquillo J, Poca MA, Amoros S: Current aspects of pathophysiology and cell dysfunction after severe head injury. Curr Pharm Des 2001, 7:1475-1503.
28. Morganti-Kossmann MC, Rancan M, Otto Vl, Stahel PF, Kossmann T: Role of cerebral inflammation after traumatic brain injury: a revisited concept. Shock 2001, 16:165-177.

29. Shojo H, Kaneko Y, Mabuchi T, Kibayashi K, Adachi N, Borlongan CV: Genetic and histologic evidence implicates role of inflammation in traumatic brain injury-induced apoptosis in the rat cerebral cortex following moderate fluid percussion injury. Neuroscience 2010, 171:1273-1282.

30. McKeating EG, Andrews PJ, Mascia L: Leukocyte adhesion molecule profiles and outcome after traumatic brain injury. Acta Neurochir Suppl 1998, 71:200-202.

31. Morganti-Kossmann MC, Rancan M, Stahel PF, Kossmann T: Inflammatory response in acute traumatic brain injury: a double-edged sword. Curr Opin Crit Care 2002, 8:101-105.

32. Hall ED, Bryant YD, Cho W, Sullivan PG: Evolution of post-traumatic neurodegeneration after controlled cortical impact traumatic brain injury in mice and rats as assessed by the de Olmos silver and fluorojade staining methods. J Neurotrauma 2008, 25:235-247.

33. Harlan JM: Leukocyte-endothelial interactions. Blood 1985, 65:513-525.

34. Chen T, Liu W, Chao X, Zhang L, Qu Y, Huo J, Fei Z: Salvianolic acid B attenuates brain damage and inflammation after traumatic brain injury in mice. Brain Res Bull 2011, 84:163-168.

35. Qu C, Mahmood A, Ning R, Xiong Y, Zhang L, Chen J, Jiang H, Chopp M: The treatment of traumatic brain injury with velcade. J Neurotrauma 2010, 27:1625-1634.

36. Whalen MJ, Carlos TM, Dixon CE, Schiding JK, Clark RS, Baum E, Yan HQ, Marion DW, Kochanek PM: Effect of traumatic brain injury in mice deficient in intercellular adhesion molecule-1: assessment of histopathologic and functional outcome. J Neurotrauma 1999, 16:299-309.

37. Rothlein R: Overview of leukocyte adhesion. Neurology 1997 49(Suppl 4):S3-S4

38. Diamond MS, Springer TA: A subpopulation of Mac-1 (CD11b/CD18) molecules mediates neutrophil adhesion to ICAM-1 and fibrinogen. J Cell Biol 1993, 120:545-556.

39. Edens HA, Parkos CA: Modulation of epithelial and endothelial paracellular permeability by leukocytes. Adv Drug Deliv Rev 2000, 41:315-328.

40. Johnson-Leger C, Aurrand-Lions M, Imhof BA: The parting of the endothelium: miracle, or simply a junctional affair? J Cell Sci 2000, 113:921-933.

41. Elalamy I, Chakroun T, Gerotziafas GT, Petropoulou A, Robert F, Karroum A, Elgrably F, Samama MM, Hatmi M: Circulating platelet-leukocyte aggregates: a marker of microvascular injury in diabetic patients. Thromb Res 2008, 121:843-848.

42. He $P$, Zhang H, Zhu L, Jiang Y, Zhou X: Leukocyte-platelet aggregate adhesion and vascular permeability in intact microvessels: role of activated endothelial cells. Am J Physiol Heart CircPhysiol 2006, 291:H591-H599.

43. Lehr HA, Olofsson AM, Carew TE, Vajkoczy P, von Andrian UH, Hubner C, Berndt MC, Steinberg D, Messmer K, Arfors KE: P-selectin mediates the interaction of circulating leukocytes with platelets and microvascular endothelium in response to oxidized lipoprotein in vivo. Lab Invest 1994 71:380-386

44. Moore KL, Patel KD, Bruehl RE, Li F, Johnson DA, Lichenstein HS, Cummings RD, Bainton DF, McEver RP: P-selectin glycoprotein ligand-1 mediates rolling of human neutrophils on P-selectin. J Cell Biol 1995, 128:661-671.

45. Ishikawa M, Kusaka G, Yamaguchi N, Sekizuka E, Nakadate $H$, Minamitani H, Shinoda S, Watanabe E: Platelet and leukocyte adhesion in the microvasculature at the cerebral surface immediately after subarachnoid hemorrhage. Neurosurgery 2009, 64:546-553.

46. van der Sande JJ, Emeis JJ, Lindeman J: Intravascular coagulation: a common phenomenon in minor experimental head injury. J Neurosurg 1981, 54:21-25.

47. Holmin S, Soderlund J, Biberfeld P, Mathiesen T: Intracerebral inflammation after human brain contusion. Neurosurgery 1998, 42:291-298.

48. Clark RS, Schiding JK, Kaczorowski SL, Marion DW, Kochanek PM: Neutrophil accumulation after traumatic brain injury in rats: comparison of weight drop and controlled cortical impact models. J Neurotrauma 1994, 11:499-506.

49. Carlos TM, Clark RS, Franicola-Higgins D, Schiding JK, Kochanek PM: Expression of endothelial adhesion molecules and recruitment of 
neutrophils after traumatic brain injury in rats. J Leukoc Biol 1997, 61:279-285.

50. Holmin S, Mathiesen T, Shetye J, Biberfeld P: Intracerebral inflammatory response to experimental brain contusion. Acta Neurochir(Wien) 1995, 132:110-119.

51. Soares HD, Hicks RR, Smith D, McIntosh TK: Inflammatory leukocytic recruitment and diffuse neuronal degeneration are separate pathological processes resulting from traumatic brain injury. J Neurosci 1995, 15:8223-8233.

52. Arumugam TV, Salter JW, Chidlow JH, Ballantyne CM, Kevil CG, Granger DN: Contributions of LFA- 1 and Mac- 1 to brain injury and microvascular dysfunction induced by transient middle cerebral artery occlusion. Am J Physiol Heart Circ Physiol 2004, 287:H2555-H2560.

53. Matsuo Y, Onodera H, Shiga Y, Shozuhara H, Ninomiya M, Kihara T, Tamatani T, Miyasaka M, Kogure K: Role of cell adhesion molecules in brain injury after transient middle cerebral artery occlusion in the rat. Brain Res 1994, 656:344-352.

54. Prestigiacomo CJ, Kim SC, Connolly ES Jr, Liao H, Yan SF, Pinsky DJ: CD18mediated neutrophil recruitment contributes to the pathogenesis of reperfused but not nonreperfused stroke. Stroke 1999, 30:1110-1117.

55. Bramlett HM, Dietrich WD: Pathophysiology of cerebral ischemia and brain trauma: similarities and differences. J Cereb Blood Flow Metab 2004 24:133-150

56. Lighthall JW, Dixon CE, Anderson TE: Experimental models of brain injury. I Neurotrauma 1989, 6:83-97.

57. Carbonell WS, Maris DO, McCall T, Grady MS: Adaptation of the fluid percussion injury model to the mouse. J Neurotrauma 1998, 15:217-229.

58. Dietrich WD, Alonso O, Halley M: Early microvascular and neuronal consequences of traumatic brain injury: a light and electron microscopic study in rats. J Neurotrauma 1994, 11:289-301.

59. Dixon CE, Clifton GL, Lighthall JW, Yaghmai AA, Hayes RL: A controlled cortical impact model of traumatic brain injury in the rat. J Neurosci Methods 1991, 39:253-262.

doi:10.1186/1742-2094-10-32

Cite this article as: Schwarzmaier et al: In vivo temporal and spatial profile of leukocyte adhesion and migration after experimental traumatic brain injury in mice. Journal of Neuroinflammation 2013 10:32.

\section{Submit your next manuscript to BioMed Central and take full advantage of:}

- Convenient online submission

- Thorough peer review

- No space constraints or color figure charges

- Immediate publication on acceptance

- Inclusion in PubMed, CAS, Scopus and Google Scholar

- Research which is freely available for redistribution 